\title{
Activities of the Professoriate: A new perspective on scholarship
}

\author{
Oyeyemi, A. \\ School of Health Professions, Hunter College, 425 East $25^{\text {th }}$ Street, Box 610, New York, NY 10010 \\ Correspondence \\ Susan McKinney Nursing and Rehabilitation Center, 590 Albany Avenue, Brooklyn, NY 11203 \\ Email:oyeyemia@nychhc.org・adeoyeyemi@aol.com
}

\begin{abstract}
SUMMARY
A persistent presumption is that research activity solely constitutes scholarship, with the exclusion of teaching and service, the other two activities of the professoriate. The purpose of this review is to promote aw areness on the multidimensional nature of scholarship.

This paper presents an observable trend on the subject of scholarship among academics, with particular reference to physiotherapy practice and teaching. It outlines the three requirements of scholarly activity, and elucidates on the scholarship of discovery, the scholarship of application, the scholarship of integration and the scholarship of teaching and learning. It also offers an insight into the activities that are considered scholastic and those that are not.

The scholarship of teaching is an option open to the entire professoriate. The physiotherapy academicians and clinicians are challenged to embrace true scholarship.
\end{abstract}

KEY WORDS: scholarship, discovery, integration, teaching, learning, application

\section{INTRODUCTION}

A general presumption is that the quality of education provided in a training institution does not only depend on its teachers, but also on the atmosphere in which the training is provided. Within a programme, the combined efforts of content experts in clinical and non-clinical subject areas is necessary to produce graduates that are well prepared to deliver health care in the contemporary world. Science and professional education in medicine and health are deemed best when conducted in an atmosphere where trainers are appreciative of the multiple styles of thinking, and diverse social concepts and values. Academicians are expected to demonstrate abilities and behaviour that reflect a commitment to excel in meeting the expectations of their institution, students, profession or discipline, and the community at large. An ideal learning environment is one that is fortified by the opportunity to learn from, and be influenced by teachers in the areas of knowledge within and outside of a discipline. Only in such an atmosphere can students be best trained to identify and fulfill their responsibilities and obligations to the society.

In essence, professional education must be conducted in an environment that fosters intellectual challenge, curiosity, a spirit of enquiry and excellence in practice, characteristic of a community of scholars. The mission of the institution and the training programme must be compatible and mutually supportive. Such an institution and programme must be ones that provide opportunity for turning out rounded products.

\section{Defining Scholarship}

Scholarship, according to The American Heritage Dictionary (2006), is the method, discipline and achievement of a scholar(s) or the knowledge resulting from the study, discipline and research in a field. It is a generic term used to describe the activities of the mind and spirit of academicians and students or the 'people of knowledge'. For an activity to constitute scholarship, it must be made public, must submit to critical reviews and evaluation and be accessible to peers for exchange and use (Boyer, 1990; Lindstrom, 1996).

When properly communicated and critiqued, scholarship could be regarded as the building block of knowledge growth in a field. Scholarship applied to health professionals must also be viewed within the context of the elements of professionalism. A baseline requirement for success among academic physiotherapists is therefore a combination of advanced education, licensure, specialization, and attributes such as concern for quality, 
client advocacy and peer relationship. These attributes must be embodied in those who impart knowledge to students.

A general consensus is that knowledge may be acquired not only through research, but also through practice and teaching (Boyer, 1990; Graves, 1992; Evans, 1994). Scholars are therefore expected to establish the need for knowledge acquisition, popularize the awareness to explore the frontiers of knowledge, integrate ideas, and link theory and practice.

\section{A Broad View of Scholarship Paradigm shift}

Scholarship in the past was characterized by a disproportionate focus on research productivity, which has 'unbalanced' the work of the academia. Prior to the last two decades, debates among academics were centred mainly on teaching versus research (Boyer, 1990; Graves, 1992). A scholar, therefore, tended to be viewed more in the light of research publications than the other component activities of the professoriate - teaching and service.

Debates initiated a little over a decade ago sought to change the dominant view that to be a scholar is solely to be a researcher. University teachers were challenged to assume a primary responsibility for giving scholarship a richer and more vital meaning. Ernest Boyer (1990) espoused a broadened view of scholarship to include four distinct but interrelated parts: the scholarship of I) discovery, ii) application, iii) integration, and iv) teaching.

\section{Scholarship of discovery}

Scholarship of discovery is the pursuit of new knowledge encompassing all aspects of research and investigation. At its best, it contributes not only to the stock of human knowledge, but also to the intellectual climate of a university. Research activity has been described as an important mode of teaching and a valuable means of learning (Evans, 1994; Bowden, 2007).

Scholarship of discovery thrives best when an institution supports the pursuit of knowledge for its own sake, and allows freedom of inquiry and liberty to follow an investigation wherever it may lead. Scientific investigations in physiotherapy and rehabilitation further our understanding of illness and disability prevention, function restoration, and the promotion of general health and quality of life.

Among academics, research publication is critical for promotion and tenure, and is often the sole yardstick for measuring success among budding scholars. The quality of a research study publication may be determined by its level on an evidence hierarchy. A general consensus is that randomized control trials, longitudinal and meta-analytic review studies rank higher than cross-sectional and casecontrol studies (Atkins et al, 2004).

\section{Scholarship of engagement/application}

Scholarship of engagement/application relates to the concept of service, and involves the rigorous application of academic expertise to the problems that affect individuals, institutions, and the society (Boyer, 1990; Lindstrom, 1996; Bowden, 2007). This aspect of scholarship refers to clinical services and related activities in which theory and practice interact to generate new intellectual insights.

Scholarly service is serious and demanding work, that requires the rigour and accountability traditionally associated with research activity. It addresses local, state, national, and international challenges in health care. Scholarship of application is distinct from citizenship activities, that are meritorious social and civic functions also deserving of appropriate recognition. Performing routine treatment in a clinic or hospital in the usual and standard manner does not constitute scholarly activity. Activities in elective/appointed positions in government or professional organizations are not deemed scholarly (Lindstrom, 1996; Bowden, 2007; ASHE, 2002).Therefore, regular committee work in the administration of a university does not constitute scholarly activity. Development of innovative techniques or treatment approaches, modification of an existing approach that results in improved outcomes are examples of excellent scholarly service. However, any new technique, approach or modification that is not publicized, or evaluated and reviewed by peers, or made accessible for exchange and use by practitioners, is not scholarly.

\section{Scholarship of integration}

This type of scholarship connects knowledge and discovery in larger patterns and contexts and creates new perspectives (Boyer, 1990; Lindstrom, 1996). Scholarship of integration involves research at the boundary where disciplines converge. An activity is deemed scholastic in the area of integration if it connects technology with teaching and research. Educating non-specialists and interpreting research in a way that places findings in the realm of the society or community, are possible scholastic activities in the area of integration. 
Supposing research establishes that the common practice of sweeping, involving trunk flexion, predisposes street cleaners to early onset of disabling low back pain compared to another technique; activities that can lead to widespread acceptance of this safe technique among street cleaners or the general population is potentially scholastic. Documented activity such as education that could lead to the adoption of a safe practice capable of reducing the risk of a problem is scholastic, provided it is reported in an appropriate forum, made public and is peer-accessible for critique.

\section{Scholarship of teaching}

Effective teaching begins with a syllabus, course objectives, course content sequence, testing methods and schedules. In reality, teaching entails the use of appropriate methods, including didactic or experiential techniques, due consideration for learning styles and generational differences in outlook. The scholarship of teaching, more than excellent teaching, comes about when a faculty poses and systematically investigates questions related to teaching improvement and student learning (Huntchinger and Shulman, 1999; McCroskey et al, 2002, Salvatori, 2002).

Scholarship of teaching and learning involves stages of planning, assessing, and modifying one's teaching. It entails an understanding of what theories, values and principles underpin or spring from a teaching practice. Scholarly teaching involves the application of the same standard that is used in research in evaluating a portfolio (Clark, 1997; Shulman, 1998; Richlin, 2001; Huber, 2004). Such a portfolio must be made public, susceptible to critical reviews and evaluation and accessible to peers for exchange and use. The scholarship of teaching involves both educating and enticing future scholars. It begins with what the teacher knows, and therefore, requires individuals who are well-informed about the latest advances in their fields. At its best, scholarly teaching involves not only transmitting knowledge, but also transforming and extending knowledge through study and debate. Scholarly teachers establish clear goals for a course, focusing on what the student will learn rather than the content they will cover.

\section{DISCUSSION}

A broad perspective on scholarship does not focus solely on research as the most valued scholastic activity. It reaffirms the commitment to scholarship and assists academicians in assessing how scholarship is defined, evaluated and rewarded. A broad view of scholarship acknowledges the full range of faculty talents required to accomplish the diverse functions of a university. It challenges academicians in physiotherapy and other allied health disciplines to keep abreast of developments in their field, remain professionally active, and expect to be held up to the highest standards of integrity in every aspect of their work.

It could be argued that unlike qualitative studies, researchers from the developing countries may be disadvantaged in contributing to knowledge in the area of research that may require state-of-the-art instruments. However, it is widely acknowledged that physiotherapy and other allied health disciplines have universal and local practice components. Research and investigation in identified local components of practice will always be needed and knowledge in these areas can be worth disseminating to the global community of peers.

Scholarship of teaching is often misconstrued. One misconception is that only teachers in the education discipline should demonstrate scholarship in teaching. Is scholarship of teaching even an option open to nonteaching disciplines? The answer to this question is 'Yes'. This is because physiotherapy and allied health subjects are not taught by those who hold degrees in education, and clinicians are not 'generic' teachers. Yet, teachers as mentors share the responsibility for student learning with the mentees under their tutelage.

For physiotherapy clinicians and academicians, teaching problems may not be so easy to identify or may be ignored. A relevant teaching question could be: how best can students be made to cultivate a specific generic ability such as empathy, or how can the passing rate on a subject or topic, historically identified to be difficult for the student to master or grasp, be improved? Following the identification of a problem or topic in teaching needing study, a thesis for resolving the problem should be proposed and tested. The result of the study should be documented and the written documentation should then be evaluated.

Scholarship at its best should bring faculties together, creating a community of scholars working toward a shared vision of intellectual and social possibilities. Physiotherapy scholars are needed to establish the need and popularize the awareness to explore the frontiers of knowledge in this discipline. Scholars are needed to integrate ideas, connect theory and practice and inspire students. A broadened notion of scholarship serves as an opportunity through which the scholarship horizons of academicians can be expanded. 
Physiotherapy clinicians and academicians share the responsibility to stimulate active learning and encourage students to be critical and creative thinkers, as they develop the capacity for a lifetime of learning. Physiotherapy training institutions, including universities and clinical sites, must be geared to grow such scholars. Academic physiotherapists should be encouraged to acquire teacher training skills, and could also collaborate with their counterparts in education to promote the scholarship of pedagogy.

\section{References}

American Society of Higher Education (ASHE) (2002) A broad view of scholarship through Boyer's four domains Appendix B. The Inventory of Scholarship, ASHE-ERIC Higher Education Report 29; Hoboken, NJ. John Wilkins \& Sons. 96.

Atkins, D., Best, D., Brass, P.A. et al (2004) Grading quality of evidence and strength of recommendations. British Medical Journal 328(7454), pp.1490-5.

Bowden, R.G. (2007) Scholarship Reconsidered. Journal of the Scholarship of Teaching and Learning 7(2), pp.1-21.

Boyer, E.B. (1990) Scholarship Reconsidered: priorities of the professoriate. The Carnegie Foundation for the Advancement of Teaching, Lawrenceville, New Jersey, Princeton University Press, pp.1-67.

Clark, C.B. (1997) The modern integration of research activities into teaching and learning. Journal of Higher Education 68(3): 244-255.

Evans, L. (1994) Redefining scholarship: It is a faculty responsibility.American Journal of Pharmaceutical Education 58, pp.238-241.
Graves, N. M. (1992) Redefining scholarship: A faculty member's perspective. American Journal of Pharmaceutical Education 56, pp.450-453.

Huber, M.T. (2004) Balancing acts: The scholarship of teaching and learning in academic careers. Washington DC: American Association of Higher Education and Carnegie Foundation for the Advancement of Teaching. 1-6.

Hutchinger, P. and Shulman, L.S. (1999) The scholarship of teaching: new elaboration, new development. Change 5, pp.11-15.

Lindstrom, R.E. (1996) Innovations in teaching. American Journal of Pharmaceutical Education; 60, 77-79.

McCrosky, L.L., Richmond, V.P. and McCrosky, J.C. (2002) The scholarship of teaching and learning. Contributions form the discipline of communication. Communication Education 51, pp.383-391.

Richlin, L. (2001) Scholarly teaching and the scholarship of teaching. In: Kreber, C. (ed.) Scholarship Revisited: perspectives on the scholarship of teaching. New directions for teaching and learning. 86 Hoboken, NJ, John Willey \& Sons, pp.128-132.

Salvatori, M.R. (2002): The scholarship of teaching: Beyond the anecdotal. Pedagogy 2(3), pp.297-310.

Shulman, L.S. (1998) Course anatomy: The dissection and analysis of knowledge through teaching. In: Hatchings, P. (ed.) The Course Portfolio: How Instructors Can Examine Their Teaching to Advance Practice and Improve Students Learning. Washington D.C., American Association for Higher Education. pp.23-28.

The American Heritage Dictionary of the English Language (2006) $4^{\text {th }}$ ed. Houghton Mifflin. 